\title{
Awareness on Recent Advances in Materials Used in Maxillofacial Prosthesis Among Undergraduate Dental Students - A Cross Sectional Survey
}

\author{
Md Sohaib Shahzan ${ }^{1}$, Revathi Duraisamy² and Dhanraj Ganapathy ${ }^{3}$ \\ ${ }^{1}$ Saveetha Dental College and Hospitals Saveetha University of Medical and \\ Technical Science(SIMATS) Saveetha University. Chennai-600077, India. \\ ${ }^{2}$ Senior Lecturer, Department of Prosthodontics, Saveetha Dental College \\ and Hospitals Saveetha University of Medical And Technical Science(SIMATS) \\ Saveetha University. Chennai-600077, India. \\ ${ }^{3}$ Professor and Head, Department of Prosthodontics, Saveetha Dental College and \\ Hospitals, Saveetha Institute of Medical and Technical Sciences(SIMATS), \\ Saveetha University, 162, PH road, Chennai-600077, Tamilnadu , India,
}

\section{ABSTRACT}

The aim of this study was to assess the awareness on recent advances in materials used in maxillofacial prosthesis among dental students. Maxillofacial deformities are embarrassing to patients and may negatively affect their physical and physiological health, potentially resulting in serious psychiatric, familial and social problems. Maxillofacial prosthesis have an impact on the patient's quality of life. Several materials, techniques and clinical approaches have been used for maxillofacial prosthesis. So this study aims at evaluating the awareness on recent advances in materials used in maxillofacial prosthesis among undergraduate students of saveetha dental college. A set of 10 questionnaires was framed and an online survey was conducted among Saveetha dental college students using survey planet.100 students have taken the survey and the results were statistically analysed from the responses. From the results, 57\% of students were not aware about the recent advances in materials for maxillofacial prosthesis. 59\% students were aware of silicone block polymer but 57\% were not aware about its properties. 53\% students were not aware about polyphosphazenes. 56\% were not aware about A-2186 (Factor 11) and silphenylenes. 78\% students agree that the future of maxillofacial prosthesis depends on the development of new materials. Hence, the study draws attention that the students are not aware about recent advances of materials used in maxillofacial prosthesis. We need to create more awareness by seminars, $\mathrm{CDE}$ programs and hands on lectures on recent advances in maxillofacial prosthesis.

KEY WORDS: RECENT ADVANCES; MAXILLOFACIAL; A-2186; POLYPHOSPHAZENES; SIL PHENYLENES.

\section{ARTICLE INFORMATION}

*Corresponding Author: revathid.sdc@saveetha.com

Received 5th Aug 2020 Accepted after revision 28th Sep 2020

Print ISSN: 0974-6455 Online ISSN: 2321-4007 CODEN: BBRCBA

Thomson Reuters ISI Web of Science Clarivate Analytics USA and Crossref Indexed Journal

$$
\begin{gathered}
\text { Clarivate } \\
\text { Analytics }
\end{gathered}
$$

NAAS Journal Score 2020 (4.31) SJIF: 2020 (7.728)

A Society of Science and Nature Publication,

Bhopal India 2020. All rights reserved.

Online Contents Available at: http//www.bbrc.in/

Doi: http://dx.doi.org/10.21786/bbrc/13.8/191 


\section{INTRODUCTION}

Since the sixteenth century, any surgical imperfections have been reestablished by prosthetic substitutions built from an assortment of materials(Anusavice, Shen and Ralph Rawls, 2014). Maxillofacial prosthetics is defined as that branch of prosthodontics concerned with restoration and replacement of both of stomatognathic and associated facial structures by artificial substitutes that may or may not be removed('The glossary of prosthodontic terms', 2005). It envelops prosthetic restoration of patients with oral or facial absconds which might be normally obtained or may result from malady or injury. A number of materials are accessible and have been utilized for creation of maxillofacial prosthesis.

These incorporate wood, wax, metals and as of late polymers. Polymers and elastomers are the pillar of current maxillofacial prosthetic recreation(S et al., 2015). Polymethylmethacrylate, polydimethylsiloxane and polyether urethanes have been tried and utilized in satisfying the need for materials that will be biocompatible, strong, shading stable and effectively manipulated (Lontz, 1990). The new materials have shown some great properties yet in addition some disappointing insufficiencies. Up 'till now, a material has not developed that doesn't have unwanted qualities. Much exertion has been consumed as of late in contemplating existing materials with expectations of improving their insufficiencies.

The success of the prosthetic rehabilitation of the facial defect is limited by mechanical and physical properties of the material selected for that purpose(Alqutaibi, 2015).Commonly used materials for construction of facial prosthesis include but not limiting to: Acrylic resins and its copolymers, vinyl polymers, polyurethane elastomers, and silicone elastomers, unfortunately none of them fulfill all the ideal requirements for a satisfactory prosthesis(Alqutaibi, 2015). In general, the ideal material for extra oral prosthesis include: Biocompatible not irritating the surrounding tissues, yet it should be strong enough about the periphery to endure, be translucent, lightweight, easy to process, and easy to manipulate prior to processing(Maller, Karthik and Maller, 2010). It should be resistant to various chemicals such as ether and oils and to sunlight, heat, and cold (Taylor, 2000).

Ideal physical and mechanical properties of the maxillofacial materials include High edge strength, high elongation, high tear strength, softness, compatible to tissue, and translucent (Chalian and Phillips, 1974). Ideal processing characteristics of the maxillofacial materials include Chemically inert after processing, ease of intrinsic and extrinsic coloring with commercially available colorants, long working time, no color change after processing, reusable molds and Retain intrinsic and extrinsic coloration during use(Chalian and Phillips, 1974; Moore et al., 1977). Ideal biological properties of the maxillofacial materials include Non-allergenic, cleansable with disinfectants, color stability, inert to solvents and skin adhesives, and resistance to growth of microorganisms.(Chalian and Phillips, 1974; Stansbury and Antonucci, 1992)

Face is the patient's contact with the world and it forms the physical basis for personal recognition. As the father of Indian surgery Sushrutha Samhitha said hundreds of years ago, "the love of face is next only to the love of our life and thus the mutilated cry for help." Thus, people having severely disfigured or missing parts of the maxillofacial skeleton or the face in particular come for a normal appearance by artificial restorations to us. Today, with the improved knowledge, skill, materials and technique in the dentistry, it has become easy to rehabilitate oral, and facial defects with the maxillofacial prosthesis.The UG students should be aware of recent advancements in materials and even technologies used for maxillofacial prosthesis so more research can be carried out to develop new treatment techniques and assess outcomes have improved treatment strategies.

Previously our department has published extensive research on various aspects of prosthetic dentistry('Evaluation of Corrosive Behavior of Four Nickel-chromium Alloys in Artificial Saliva by Cyclic Polarization Test:An in vitro Study', 2017; Ganapathy, Kannan and Venugopalan, 2017; Jain, 2017a, 2017b; Ranganathan, Ganapathy and Jain, 2017; Ariga et al., 2018; Gupta, Ariga and Deogade, 2018; Anbu et al., 2019; Ashok and Ganapathy, 2019; Duraisamy et al., 2019; Varghese, Ramesh and Veeraiyan, 2019), this vast research experience has inspired us to research about we planned to pursue research on awareness on recent advances in materials used in maxillofacial prosthesis among dental students. In this study we asked the students about some of the recent advances in materials like silicone block polymers, polyphosphazenes,A-2186 (Factor 11), silpheniles and their properties to assess the awareness on recent advances in materials used in maxillofacial prosthesis among dental students .

\section{MATERIAL AND METHODS}

This cross sectional survey was conducted among dental undergraduate students from December 2019 to April 2020. consisting of 10 questions (Table 1) which were passed on to the samples using survey planet to the sample size of 100 dental undergraduate students. The measure taken to minimize sampling bias was the technique of stratification and randomisation. The Institutional Review Board of Saveetha Institute of Medical and Technical Sciences, Chennai, India in January 2020 , was granted the ethical permission and approval for the project (SDC/SIHEC/2020/0619-0320). Total number of participants of the survey was 100 . All of the participants were ensured to have answered all 10 questions in the questionnaire and none of the participants were excluded from the study. Hence, 100 responses were analysed.The survey included the students who were attending clinical rotations and excluded the students in their preclinical years. 
Dental undergraduate students (3rd years, final years and interns), Saveetha dental college were the target participants of the study. The results were statistically analyzed through pie-charts and percentage analysis were obtained.

Table 1. Questionnaire as follows

Q1. Are you aware of recent advances in materials used in maxillofacial prosthesis?

A. Yes

B. B)No

Q2. Are you aware of silicone block copolymers?

A)Yes

B)No

Q3. Are you aware that silicone block copolymers are more tear resistant and have potential to support bacterial and fungal growth than silicone elastomers?

A) Yes

B) No

Q4.Are you aware of polyphosphazenes?

A. Yes

B. No

Q5.Are you aware that polyphosphazens are used as a resilient denture liner besides maxillofacial prosthesis?

A. Yes

B. No

Q6.Are you aware of A-2186 (Factor 11) a recently developed material?

A. Yes

B. No

Q7.Did you know when A-2186(Factor II) when subjected to environmental variables did not retain its improved properties ?

A. Yes

B. No

Q8.Are you aware of silphenylenes?

A. Yes

B. No

Q9 Are you aware of the property of superior coloration of silphenylenes which feel like skin in maxillofacial prosthesis ?

A. Yes

B. No

Q10.Do you agree that the future of maxillofacial prosthesis depends on the development of new materials and techniques?

A. Yes

B. No

\section{RESULTS AND DISCUSSION}

In this study 57\% students were not aware of recent advances in materials used for maxillofacial prosthesis (Figure 1). 59\% students are aware of silicone block copolymer (Figure 2) but 57\% are not aware of its properties (Figure 3). 53\% students were not aware about polyphosphazenes(Figure 4).59\% students were not aware that polyphosphazenes are used as a resilient denture liner besides maxillofacial prosthesis (Figure 5).56\% students were not aware of A-2186 (Factor 11) (Figure 6). 62\% students didn't know A-2186 (Factor II) when subjected to environmental variables did not retain its improved properties (Figure 7). 56\% students were not aware about sil phenylenes (Figure 8). 60\% students were not aware of the property of superior coloration of silphenylenes which feel like skin in maxillofacial prosthesis (Figure 9). 78\% students agree that the future of maxillofacial prosthesis depends upon development of new materials and techniques (Figure 10).

Figure 1: It was seen that $57 \%$ students were not aware of recent advances in materials used in maxillofacial prosthesis.

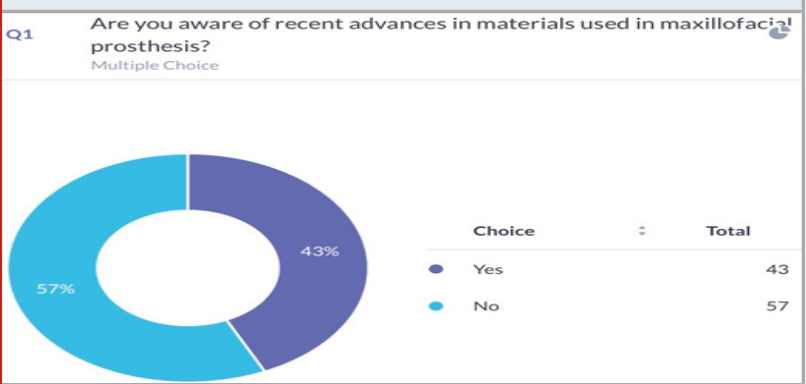

Figure 2: It was seen that 59\% students were aware of silicone block copolymer

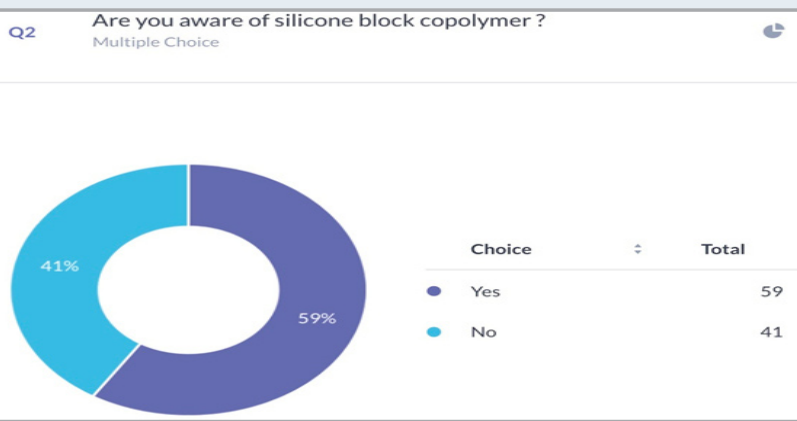

Figure 3: It was seen that 57\% students were not aware about the properties of silicone block copolymer that they are more tear resistant and have the potential to support bacterial and fungal growth.

Are you aware that silicone block copolymer are more tear resistant and have potential to support bacterial and fungal growth than silicone elastomers?

Multiple Choice

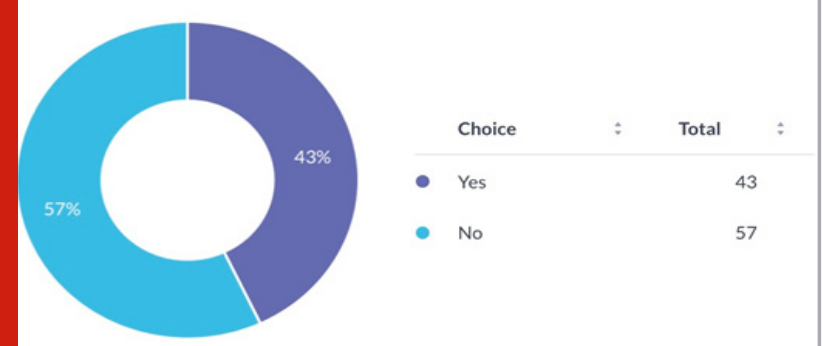


Figure 4: It was seen that 53\% were not aware about polyphosphazenes

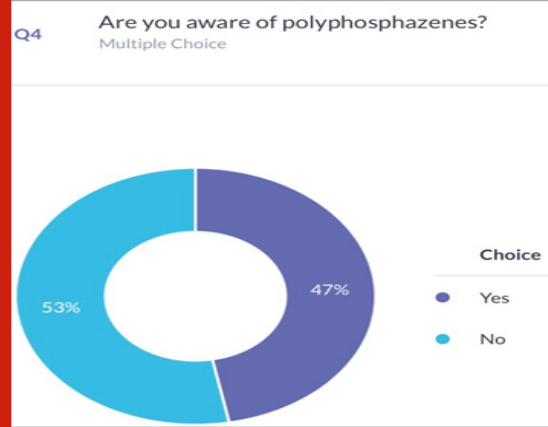

Figure 5: It was seen that 59\% students were not aware that polyphosphazenes can be used as a resilient denture liner besides maxillofacial prosthesis.

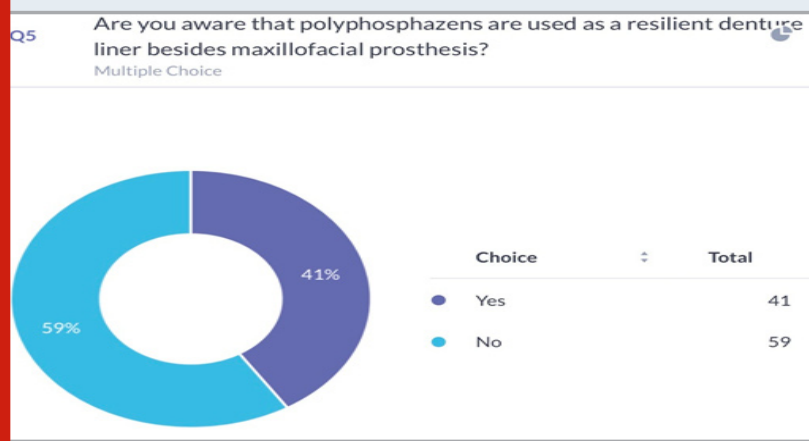

Figure 6: It was seen that 56\% students were not aware of A-2186(Factor 11) which is a recently developed material.

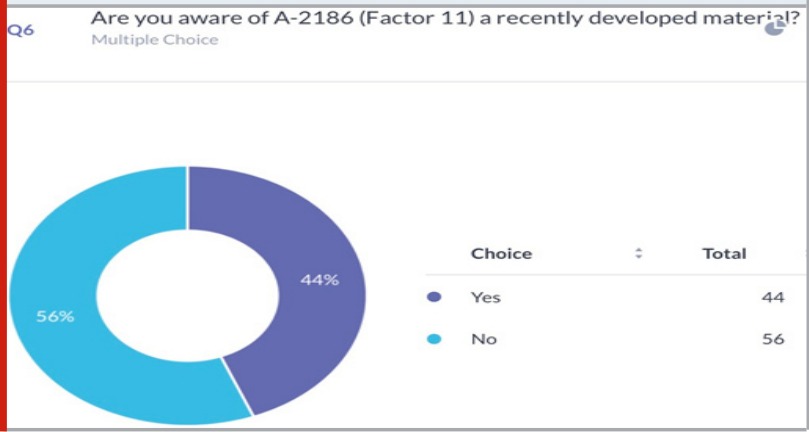

Figure 7: It was seen that $62 \%$ students were not aware that Factor II when subjected to environmental variables did not retain its improved properties

Q7 Did you know when A-2186(Factor II) when subjected to environmental variables did not retain its improved properties?
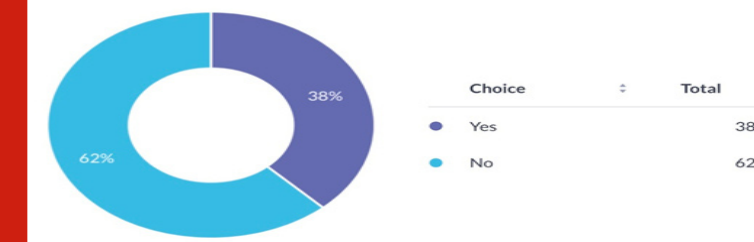

Figure 8: It was seen that 56\% students were not aware about silphenylenes

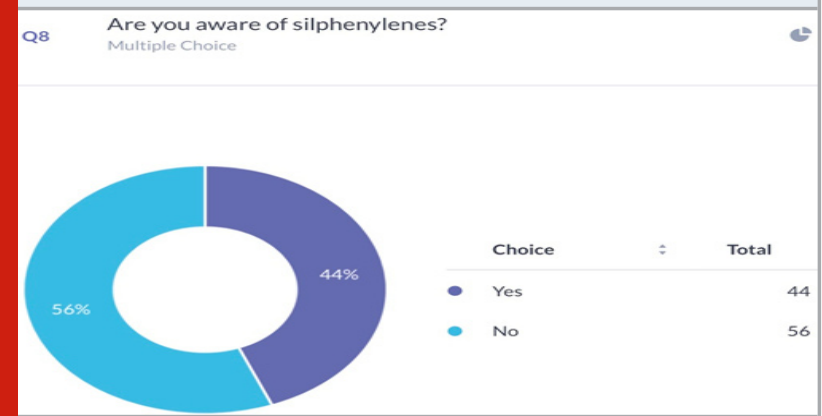

Figure 9: It was seen that 60\% students were not aware of the property of superior coloration of silphenylenes which feels like skin in maxillofacial prosthesis

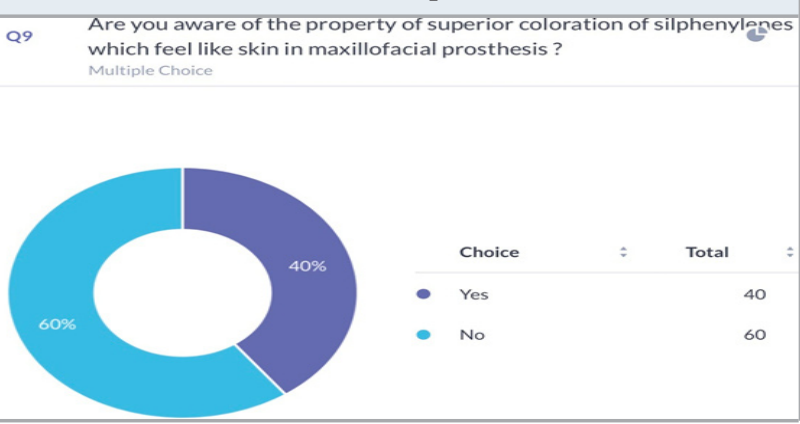

Figure 10: It was seen that $78 \%$ students agree that the future of maxillofacial prosthesis depends upon development of new materials and techniques

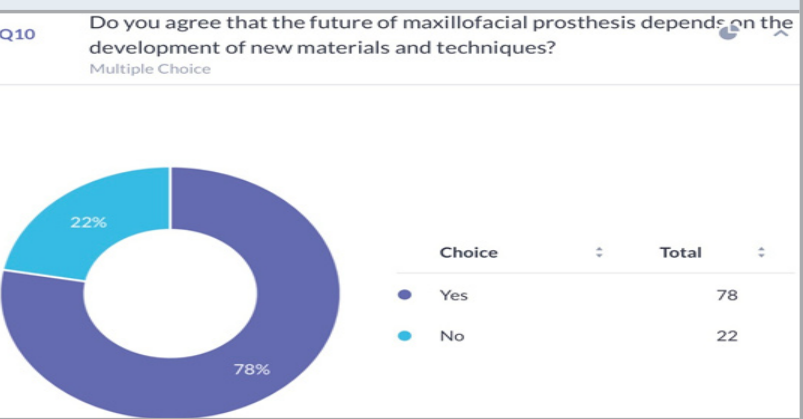

In this study 57\% students were not aware of recent advances in materials used for maxillofacial prosthesis.59\% students were aware of silicone block copolymer but 57\% were not aware of its properties. It has been introduced to improve some of the weaknesses of silicone elastomers (e.g. decreased tear strength, low percent elongation and its susceptibility to bacterial growth)(El-Kenawy and Ahmed, 2015). It is more tear resistant and has potential to support bacterial and fungal growth than silicone elastomers. Blocks of polymers other than siloxane are positioned with the traditional siloxane polymers in an attempt to modify the current physical properties of conventional silicone (Polyzois, Winter and Stafford, 1991). 
An example of this is the intertwining of polymethyl methacrylate into the chains of siloxane (Tsai et al., 1992). The improvement of the bioadhesive properties of elastomeric polydimethylsiloxane (PDMS) coatings is reported. This can be achieved by a surface modification which consists of the incorporation of block copolymers containing a PDMS block and a poly [2-(dimethylamino) ethyl methacrylate] (PDMAEMA) block in a PDMS matrix. Observations highlight the significant role of hydrophilic groups in the surface modification of silicone coatings(Kalinova, Mincheva and Dubois, 2014).

53\% students weren't aware of polyphosphazenes. Polyphosphazenes fluoroelastomer has been developed for use as a resilient liner and has the potential to be used as a maxillofacial prosthetic material. Modifications of physical and mechanical properties of these elastomers may be needed to satisfy the requirements for fabrication of maxillofacial prosthesis (Gettleman et al., 1985). Researchers in New Orleans dealt with maxillofacial prosthesis, have found that compounding polyphosphazenes with little or no fillers and decreasing the ratio of acrylic to rubber yields a softer rubber, with a HDA of 25, similar to human skin(Mitra et al., 2014).56\% students were not aware of A-2186(Factor 11).

A-2186, which is made by modification of the polymer chain had greater tear resistance, tensile strength, a larger percentage of elongation and also proved to be softer at the surface than HTV silicones and many other RTV silicones. It also demonstrated absence of cytotoxicity in the cell culture tests(Polyzois, Hensten-Pettersen and Kullmann, 1994).Sara M. Zayed et al concluded that the incorporation of surface treated SiO2 nanoparticles at concentration of 3\% enhanced the mechanical properties of A-2186 silicone elastomer(Zayed, Alshimy and Fahmy, 2014). 56\% students were not aware about sil phenylenes.Siphenylenes are siloxane copolymers that contain methyl and phenyl groups. They are formulated as a pourable, viscous, room-temperature vulcanizing liquid. In tactual response, silphenylene elastomers feel more like skin. These polymers are transparent even when reinforced with silica fillers.

These polymers possess many desirable properties of RTV silicones, including biocompatibility and resistance to degradation on exposure to ultraviolet light and heat. In addition, they exhibit improved edge strength, low modulus of elasticity and colourability.It has a property of superior coloration which feels like skin in maxillofacial prosthesis(Bansal, Khindria and Kansal, 2009; Deba, Yunus and Tamrakar, 2012; Mahajan and Gupta, 2012). 78\% students agreed that the future of maxillofacial prosthesis depends on the development of new materials.Ideal requisites for maxillo-facial materials are: 1. Materials used should be biocompatible.2. Flexibility should be flexible at temperatures from $4.4^{\circ} \mathrm{C}$ to $60^{\circ} \mathrm{C} .3$. Color and Translucency: Color should blend with the adjacent skin as close as possible. 4 . Chemical and environmental stability. 5. Thermal conductivity: Poor conductor of heat. 6. Ease of processing and ease of duplication. 7. Weight should be light and easily retained in position and be comfortable to the patient. (Reddy et al., 2015).

Limitations: The limitations of this study was, it included students from only one university and it was a short term survey, no association was made between the year of study of undergraduates and knowledge and awareness of recent advances in materials used in maxillofacial prosthesis.

Future Scope: Future scope can be a further study which takes into account a large population from various ethnicities. We can even include the post graduates and dental practitioners in a further study.

\section{CONCLUSION}

According to this survey, students were not aware about the recent advances in materials used in maxillofacial prosthesis. More awareness has to be created by conducting seminars, CDE programs and by giving hands-on lectures about recent advances in materials used in maxillofacial prosthesis.

\section{ACKNOWLEDGEMENTS}

The authors would like to acknowledge all the participants who took up the survey.

Conflict of Interest: There are no conflicts of interests to declare.

\section{REFERENCES}

Alqutaibi, A. Y. (2015) 'Materials of facial prosthesis: History and advance', Int J Contemp Dent Med Rev, 2015, p. 4.

Anbu, R. T. et al. (2019) 'Comparison of the Efficacy of Three Different Bone Regeneration Materials: An Animal Study', European journal of dentistry, 13(1), pp. 22-28.

Anusavice, K. J., Shen, C. and Ralph Rawls, H. (2014) Phillips' Science of Dental Materials - E-Book. Elsevier Health Sciences.

Ariga, P. et al. (2018) 'Determination of Correlation of Width of Maxillary Anterior Teeth using Extraoral and Intraoral Factors in Indian Population: A Systematic Review', World Journal of Dentistry, 9(1), pp. 68-75.

Ashok, V. and Ganapathy, D. (2019) 'A geometrical method to classify face forms', Journal of oral biology and craniofacial research, 9(3), pp. 232-235.

Bansal, S., Khindria, S. K. and Kansal, M. (2009) 'Maxillofacial prosthetic materials', The Journal of Indian Prosthodontic Society, p. 2. doi: 10.4103/09724052.52862.

Chalian, V. A. and Phillips, R. W. (1974) 'Materials in maxillofacial prosthetics', Journal of biomedical materials research, 8(4 Pt 2), pp. 349-363.

Deba, K., Yunus, N. and Tamrakar, A. K. (2012) 'Oral \&t Maxillofacial Prosthetics-I: Objectives \& History', Heal Talk, 4(5), pp. 18-20. 
Duraisamy, R. et al. (2019) 'Compatibility of Nonoriginal Abutments With Implants: Evaluation of Microgap at the Implant-Abutment Interface, With Original and Nonoriginal Abutments', Implant dentistry, 28(3), pp. 289-295.

El-Kenawy, M. H. and Ahmed, W. M. S. (2015) 'Comparison Between Physics and Conventional Forceps in Simple Dental Extraction', Journal of maxillofacial and oral surgery, 14(4), pp. 949-955.

Evaluation of Corrosive Behavior of Four Nickelchromium Alloys in Artificial Saliva by Cyclic Polarization Test:An in vitro Study' (2017) World Journal of Dentistry, 8(6), pp. 477-482.

Ganapathy, D. M., Kannan, A. and Venugopalan, S. (2017) 'Effect of Coated Surfaces influencing Screw Loosening in Implants: A Systematic Review and Meta-analysis', World Journal of Dentistry, 8(6), pp. 496-502.

Gettleman, L. et al. (1985) 'NOVEL ELASTOMERS FOR DENTURE AND MAXILLOFACIAL PROSTHESES', in Sauer, B. W. (ed.) Biomedical Engineering IV. Pergamon, pp. 141-144.

Gupta, P., Ariga, P. and Deogade, S. C. (2018) 'Effect of Monopoly-coating Agent on the Surface Roughness of a Tissue Conditioner Subjected to Cleansing and Disinfection: A Contact Profilometric Study', Contemporary clinical dentistry, 9(Suppl 1), pp. S122S126.

Jain, A. R. (2017a) 'Clinical and Functional Outcomes of Implant Prostheses in Fibula Free Flaps', World Journal of Dentistry, 8(3), pp. 171-176.

Jain, A. R. (2017b) 'Prevalence of Partial Edentulousness and Treatment needs in Rural Population of South India', World Journal of Dentistry, 8(3), pp. 213-217.

Kalinova, R., Mincheva, R. and Dubois, P. (2014) 'Imparting Adhesion Property to Silicone Materials', Reviews of Adhesion and Adhesives, 2(1), pp. 30-55. Lontz, J. F. (1990) 'State-of-the-art materials used for maxillofacial prosthetic reconstruction', Dental clinics of North America, 34(2), pp. 307-325.

Mahajan, H. and Gupta, K. (2012) 'Maxillofacial prosthetic materials: A literature review', Journal of Orofacial Research, pp. 87-90.

Maller, U. S., Karthik, K. S. and Maller, S. V. (2010) 'Maxillofacial prosthetic materials-past and present trends', J Indian Acad Dent Spec, 1(2), pp. 42-44.

Mitra, A. et al. (2014) 'Maxillofacial prosthetic materials- an inclination towards silicones', Journal of clinical and diagnostic research: JCDR, 8(12), pp. ZE08-13.

Moore, D. J. et al. (1977) 'Evaluation of polymeric materials for maxillofacial prosthetics', The Journal of prosthetic dentistry, 38(3), pp. 319-326.

Polyzois, G. L., Hensten-Pettersen, A. and Kullmann, A. (1994) 'An assessment of the physical properties and biocompatibility of three silicone elastomers', The Journal of prosthetic dentistry, 71(5), pp. 500-504.

Polyzois, G. L., Winter, R. W. and Stafford, G. D. (1991) 'Boundary lubrication and maxillofacial prosthetic polydimethylsiloxanes', Biomaterials, 12(1), pp. 7982.

Ranganathan, H., Ganapathy, D. M. and Jain, A. R. (2017) 'Cervical and Incisal Marginal Discrepancy in Ceramic Laminate Veneering Materials: A SEM Analysis', Contemporary clinical dentistry, 8(2), pp. 272-278.

Reddy, J. R. et al. (2015) 'Materials in maxillo-facial prosthesis', Journal of Indian Academy of Dental Specialist Research. India: Wolters Kluwer, pp. 2-3.

S, D. V. et al. (2015) 'Maxillofacial Prosthetic Materials -An Update', Journal of International Medicine and Dentistry, pp. 02-11. doi: 10.18320/jimd/201603.0102. Stansbury, J. W. and Antonucci, J. M. (1992) 'Evaluation of methylene lactone monomers in dental resins', Dental materials: official publication of the Academy of Dental Materials, 8(4), pp. 270-273.

Taylor, T. D. (2000) Clinical Maxillofacial Prosthetics. Quintessence Publishing Company.

The glossary of prosthodontic terms' (2005) The Journal of prosthetic dentistry, 94(1), pp. 10-92.

Tsai, F. H. et al. (1992) 'Synthesis of silicone block copolymers for use as maxillofacial materials', in Proceedings of Conference on Materials Research in Maxillofacial Prosthetics. Transactions of the Academy of Dental Materials, p. 126.

Varghese, S. S., Ramesh, A. and Veeraiyan, D. N. (2019) 'Blended Module-Based Teaching in Biostatistics and Research Methodology: A Retrospective Study with Postgraduate Dental Students', Journal of dental education, 83(4), pp. 445-450.

Zayed, S. M., Alshimy, A. M. and Fahmy, A. E. (2014) 'Effect of surface treated silicon dioxide nanoparticles on some mechanical properties of maxillofacial silicone elastomer', International journal of biomaterials, 2014, p. 750398. 